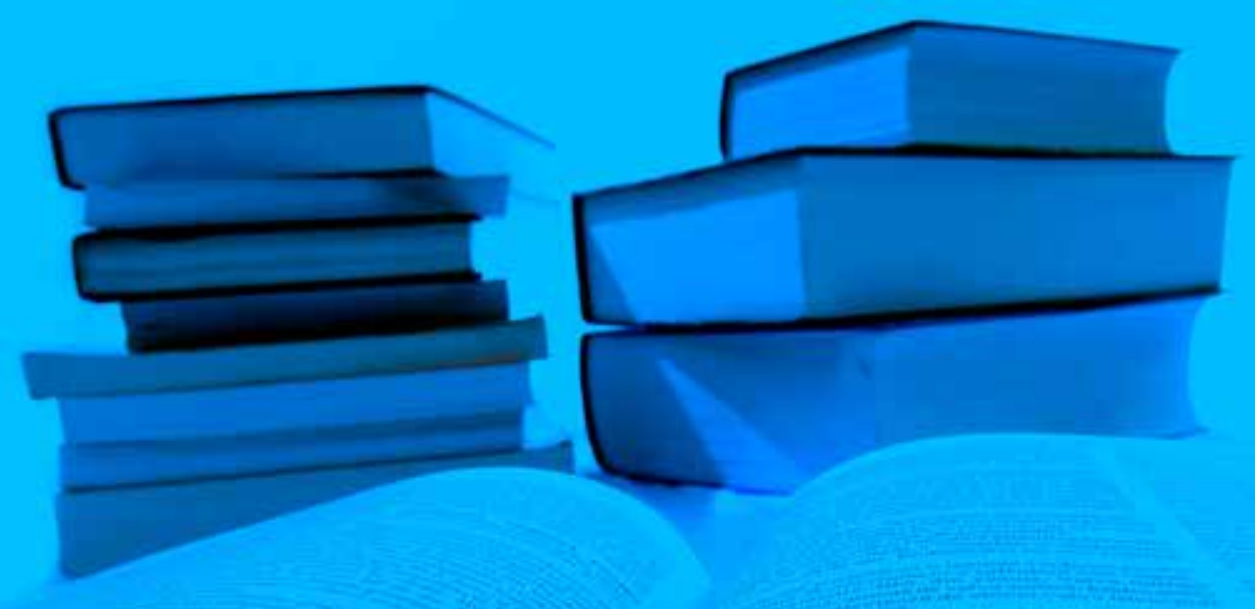

\title{
REFORMA DE LA.EDUCACIÓN SUPERIOR: LA ARISTOCRACIA DE LAS INSTITUCIONES
}

Por Eugenio Giolito, académico FEN UAH.

\section{Oe}

Finalmente, en las últimas semanas se aprobó la intención de legislar la reforma de la Educación Superior, luego que el Ejecutivo se viera obligado a introducir indicaciones sustitutivas al proyecto original después de un sinnúmero de críticas recibidas de diversos sectores.

Hace un año comentábamos que el demorado proyecto ingresado al Congreso, tenía cambios que parecian semánticos y que era difícil pronosticar que tuvieran consecuencias reales. Hoy, con las indicaciones sustitutivas aprobadas, tenemos que admitir que lo que creimos serian cambios menores fueron demasiado grandes para ciertos sectores y que además terminó en un regreso a fojas cero en varios de estos proyectos.

Un claro ejemplo de la anterior, es el cambio en las indicaciones sustitutivas de tipificación de las instituciones -que el proyecto original definía ambiguamente como "instituciones estatales", "instituciones con vocación pública" e "instituciones privadas"- y se vuelve a incluir a las instituciones del Consejo de Rectores como una categoria especial. Esta definición es solo un anticipo declarativo de lo verdaderamente importante: se retrocede con la intención de derogar el Aporte Fiscal Directo (AFD) para las instituciones creadas antes de 1981.

Recordemos que este aporte, creado a partir del DFL No 4 de 1981 del MINEDUC, se trata de un subsidio de libre disponibilidad que se asigna, fundamentalmente, en función de un criterio histórico a las 25 universidades del Consejo de Rectores. De la descripción anterior, habrá que rescatar dos palabras. Primero, que quien recibe el subsidio no está obligado a destinarlo a ningún fin en particular, más allá de un objetivo declamado de calidad académica. Segundo, que no solo quienes son beneficiarios lo son por existir antes de una determinada fecha, sino que el monto recibido (en un 95\%) está determinado de la misma forma histórica.

Si bien, este cambio puede pasar desapercibido, es difícil considerarlo criterioso ya que solamente está determinado por la repetición de lo que se viene haciendo en el pasado. Como puede verse en la Figura 1, es difícil encontrar qué características fueron tomadas en cuenta originalmente para hacer esta distribución sobre el monto por alumno para el año 2015, porque, por ejemplo, no parece que sea lineal en dimensiones académicas (varias universidades reciben más que la PUC por ejemplo), ni 
Figura 1:

Aporte Fiscal Directo por alumno (en miles de pesos). Fuente: SIES

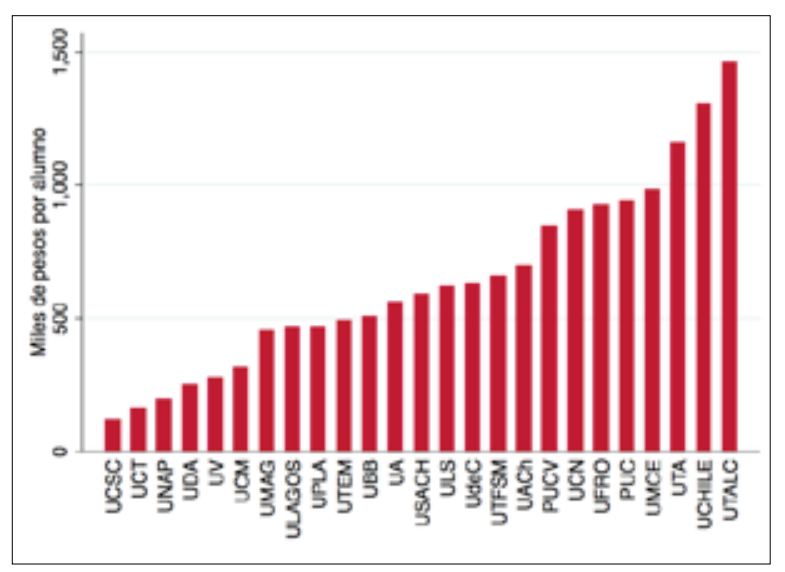

Figura 2:

Matricula total en universidades chilenas.

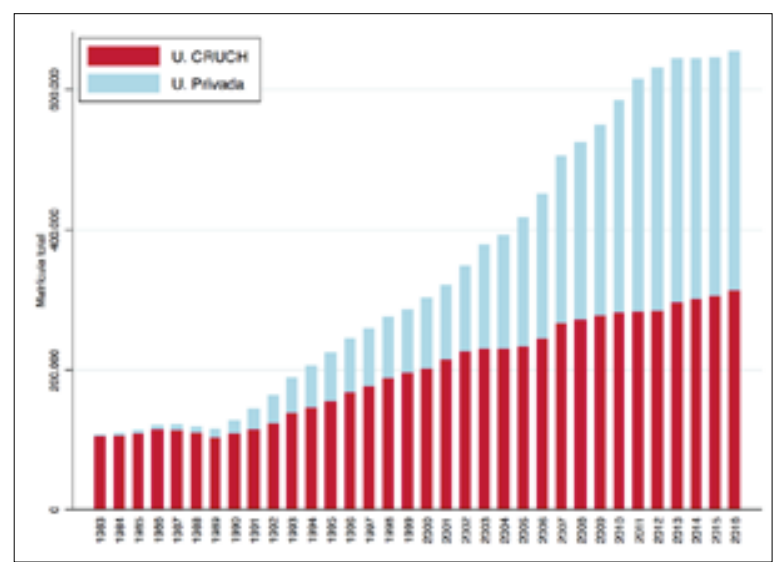

Figura 3:

Matrícula total por años de acreditación en 2016.

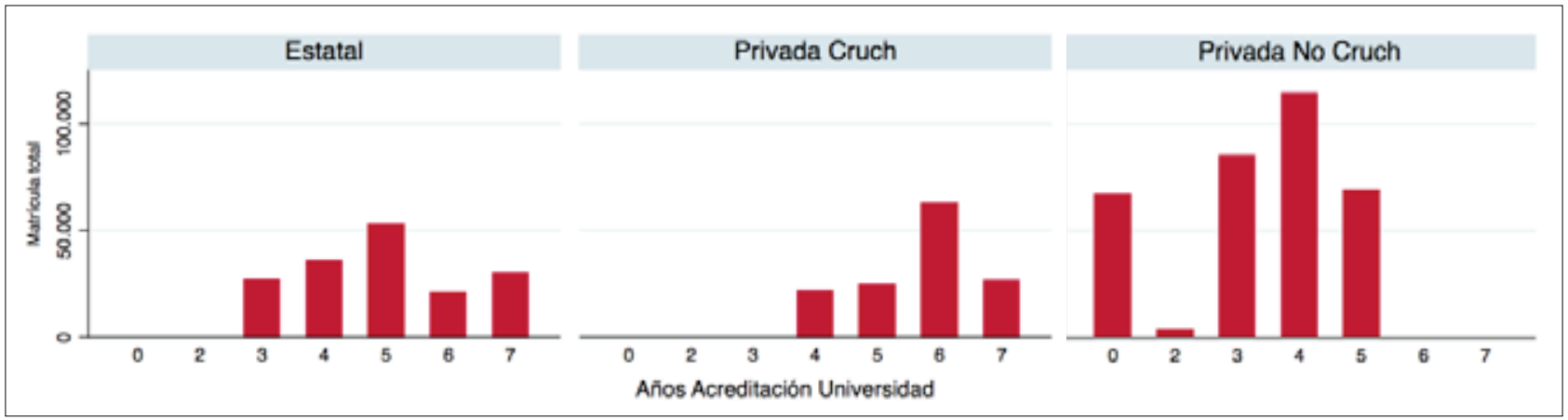

tampoco se prioriza que sean estatales.

Otro aspecto que roza el mismo tópico, es el acuerdo para la eliminación del Crédito con Aval del Estado, que despierta resistencia por la participación del sistema bancario en la financiación universitaria. Más allá que la cuestión ideólogica implícita que puede debatirse, lo que llama poderosamente la atención es que nunca se invocó como un problema que los alumnos enfrenten distintos esquemas de financiacmiento según hayan entrado en uno u otro tipo de instituciones. Recordemos que los estudiantes de las universidades del Cruch siempre tuvieron acceso al Fondo Solidario, que hasta hace pocos años tenía condiciones más ventajosas que para el resto de los estudiantes. Es legítimo pensar que la historia es el argumento preponderante para regir la legislación futura, aunque no parezca muy progresista. Nadie pone en duda que las instituciones creadas antes de 1981 han hecho su contribución al pais (algunas más que otras, por cierto), pero ¿es suficiente para atribuirle privilegios permanentes? Si fuera asi, estamos construyendo una aristocracia basada en instituciones y no en familias, pero con similares argumentos (los títulos nobiliarios suelen reconocer las guerras ganadas por los antepasados). Es también legitimo pensar que la apertura de instituciones privadas a partir de 1981 no debió haber ocurrido. Lo que no tiene mucho sentido es ver al mundo como si viviéramos en 1981. Hoy, como muestra la Figura 2, la mayoria de los estudiantes chilenos estudian en instituciones que no pertenecen al Cruch (note también que la gran expansión del sistema ocurrió en democracia, particularmente en los últimos 10 años). Es también cierto que muchos de esos estudiantes lo hacen en instituciones de escasa o dudosa calidad. Como muestra la Figura 3, el año pasado cerca de 200.000 estudiantes estaban matriculados en universidades con 3 o menos años de acreditación (de los cuales unos 30.000 lo hacian en instituciones estatales) y 70.000 lo hacian en universidades no acreditadas. Probablemente hay instituciones que no están haciendo su trabajo y prometen a miles de estudiantes un futuro que no se va a producir. Para que ello no siga ocurriendo, necesitamos un sistema que vele por los estudiantes y controle a las universidades, y los fondos que ellas reciben, exclusivamente por lo que pueden aportar a sus alumnos hoy, más que por su historia o legitimidad de origen. 